\title{
Instruments for Binge Eating Assessment in Adults: a Systematic Review
}

\author{
Instrumentos para avaliação da compulsão alimentar em \\ Adultos: uma revisão sistemática
}

Mariana Escobar ${ }^{1,2,3}$, Oellen Stuani Franzosi ${ }^{2}$, Nathália Coelho², Silvia Chwartzmann Halpern ${ }^{1,3}$, Juliana Nichterwitz Scherer ${ }^{1,3}$, Felipe Ornell ${ }^{1,3}$, Keila Maria Mendes Cereser ${ }^{3}$, Neusa Sica da Rocha ${ }^{3}$

'Drug and Alcohol Research Centre, Universidade Federal do Rio Grande do Sul, Hospital de Clínicas de Porto Alegre. Porto Alegre, Brasil.

${ }^{2}$ Nutrition and Dietetic Division, Hospital de Clínicas de Porto Alegre, Porto Alegre, Brazil ${ }^{3}$ Postgraduate Psychiatry and Behavior Sciences Program, Universidade Federal do Rio Grande do Sul (UFRGS). Porto Alegre, RS, Brasil

E-mail para contato: Mariana Escobar - nutrimariescobar@gmail.com

\begin{abstract}
Objective: The aim of this study was to systematically review the methodologies used for BE evaluation/identification diagnosis in clinical trials (CT) with adults. Methods: The search was performed on PUBMED until July 2018. The PRISMA statement was used to improve the reporting of results. Results: 93 CTs were included among the 225 studies retrieved. The main BE evaluation/identification methods used in studies were: Binge Eating Scale; Diagnostic and Statistical Manual of Mental Disorders; Eating Disorder Diagnostic Scale; Eating Disorder Examination; Eating Disorder Examination Questionnaire; Eating Disorder Inventory; Loss of Control Over Eating Scale and Three-Factor Eating Questionnaire. Overlaps between methods were observed in studies, 61 used both DSM and an evaluation instrument, 06 only DSM and 26 only standardized questionnaires to assess BE disorder. Conclusions: The DSM-5 diagnostic criterion for binge eating disorder is considered excellent and widely used, however, when the objective of the study is to identify emotional, nutritional and qualitative issues, a questionnaire or interview about subjective perceptions can be used in a complementary way.
\end{abstract}

Keywords: Diagnostic criteria. Binge eating. Binge eating diagnosis

\section{Resumo}

Objetivo: O objetivo deste estudo foi revisar sistematicamente as metodologias utilizadas para avaliação/identificação da compulsão alimentar em ensaios clínicos com pacientes adultos. Métodos: A busca foi realizada no PUBMED até julho de 2018. Foi utilizado o protocolo PRISMA para reportar os resultados. Resultados: Foram incluídos 93 ensaios clínicos dentre os 225 que foram encontrados na busca da literatura. Os principais métodos de avaliação / identificação da compulsão alimentar utilizados nos estudos foram: Binge Eating Scale; Manual Diagnóstico e Estatístico de Transtornos Mentais; Escala de Diagnóstico de Transtorno Alimentar; Exame de Transtorno Alimentar; Questionário de Exame de Transtorno Alimentar; 
Inventário de Desordens Alimentares; Escala de Perda de Controle sobre a Alimentação e Questionário de Alimentação de Três Fatores. Foram observadas sobreposições entre os métodos nos estudos, 61 utilizaram o DSM e outro instrumento de avaliação, seis estudos utilizaram apenas o DSM e 26 apenas questionários padronizados para avaliar o transtorno de compulsão alimentar. Conclusão: O critério diagnóstico do DSM-5 para o transtorno de compulsão alimentar é considerado excelente e utilizado amplamente, entretanto, quando o objetivo do estudo é identificar questões emocionais, nutricionais e qualitativas, pode ser utilizado de forma complementar um questionário ou entrevista sobre percepções subjetivas.

Palavras-chave: Critérios diagnósticos. Compulsão Alimentar. Diagnóstico de Compulsão Alimentar.

\section{INTRODUCTION}

Eating disorders (ED) are psychopathologies with multifactorial etiology, characterized by dysfunctional eating behaviors, causing imbalances in dietary pattern and attitudes. ED can lead to numerous medical complications, mostly due to late diagnosis. The main characteristic of these diseases is a change in eating behavior, which can progress to extreme thinness or obesity, among other physical and mental injuries ${ }^{1,2}$. The most studied and well-known ED are anorexia and bulimia nervosa ${ }^{2}$. Although binge eating disorder (BED) is not as studied as other eating disorders, it is the most common ED in the general population, with a lifetime prevalence estimated at $3.5 \%$ among females and $2 \%$ among males ${ }^{3}$. According to the new Diagnostic and Statistical Manual of Mental Disorders (DSM-5) ${ }^{4}$, in which BED now has its own category as an eating disorder, BED is characterized by uncontrolled intake of a large amount of food along with a sense of loss of control, which are not followed by inappropriate compensatory behaviors such as selfinduced vomiting, fasting, and extreme physical exercise. Because of that, individuals with BED usually are prone to develop overweight or obesity and are at higher risk of metabolic syndrome 5 .

Treasure et. al. ${ }^{1}$, performed a review about ED and concluded that the diagnosis of such disorders are challenging, mainly because there is an overlap of diagnostic symptoms and associated behaviors across all categories of ED. The inclusion of BED in DSM as a formal diagnosis was supported by a large body of research, and it will be very helpful to reassign many individuals to a diagnosis with greater clinical utility ${ }^{6}$. 
Take into account the difficulty of diagnosis, many authors, when conducting studies that analyze individuals with suspected BED, use DSM diagnostic criteria or other scales or questionnaires to perform the Identification. However, knowing the disparity and the variety of instruments used in the diagnosis of eating disorders, and taking into consideration that BED suffer the transition from research category to an official recognized disorder, this paper aims to systematically review the methods used to identify binge eating in adult population.

\section{METHOD}

This review was conducted according to a predetermined protocol and reported according to the Preferred Reporting Items for Systematic Reviews and MetaAnalyses (PRISMA) statement ${ }^{7}$. A search of the scientific literature was conducted through July 2018 using PUBMED health care computerized database. This search specifically focused on BE diagnosis criteria among adults in studies published in the last 5 years. Search terms included "binge eating", "compulsive eating" and "binge eating diagnosis" and respective entry terms. Inclusion criteria were peer-reviewed clinical trials, databased publications in English with available full text published in the last 5 years.

Titles, abstracts and full texts were reviewed by two independent reviewers. Disagreements regarding study inclusion were settled by a third investigator. Data were extracted independently by two reviewers using a piloted form.

We excluded studies that evaluated children, adolescents and individuals with only bulimia or anorexia nervosa. Many studies included in our review, assessed other variables beyond the binge eating. Thus, emotion, depression and craving scales reported in these studies were not presented in this review. Once the instruments and methods used for achieve the identification of BED in the included papers were retrieved, we conducted a qualitative analysis and a brief review about the major aspects of each one, in order to better understand their utility and validation.

\section{RESULTS}

\section{Literature Search and Study Selection}

The flow diagram for the selection of eligible studies is presented in Figure. 1. Through database searching, we identified 225 studies. Of these 125 were directly related to the topic of interest, and were, therefore, fully read by independent pairs 
for eligibility assessment. On further examination, 32 were excluded based on specific inclusion criteria. A total of 93 studies were included in the final qualitative analysis.

Figure 1 - PRISMA Flow Diagram of literature search and studies selection

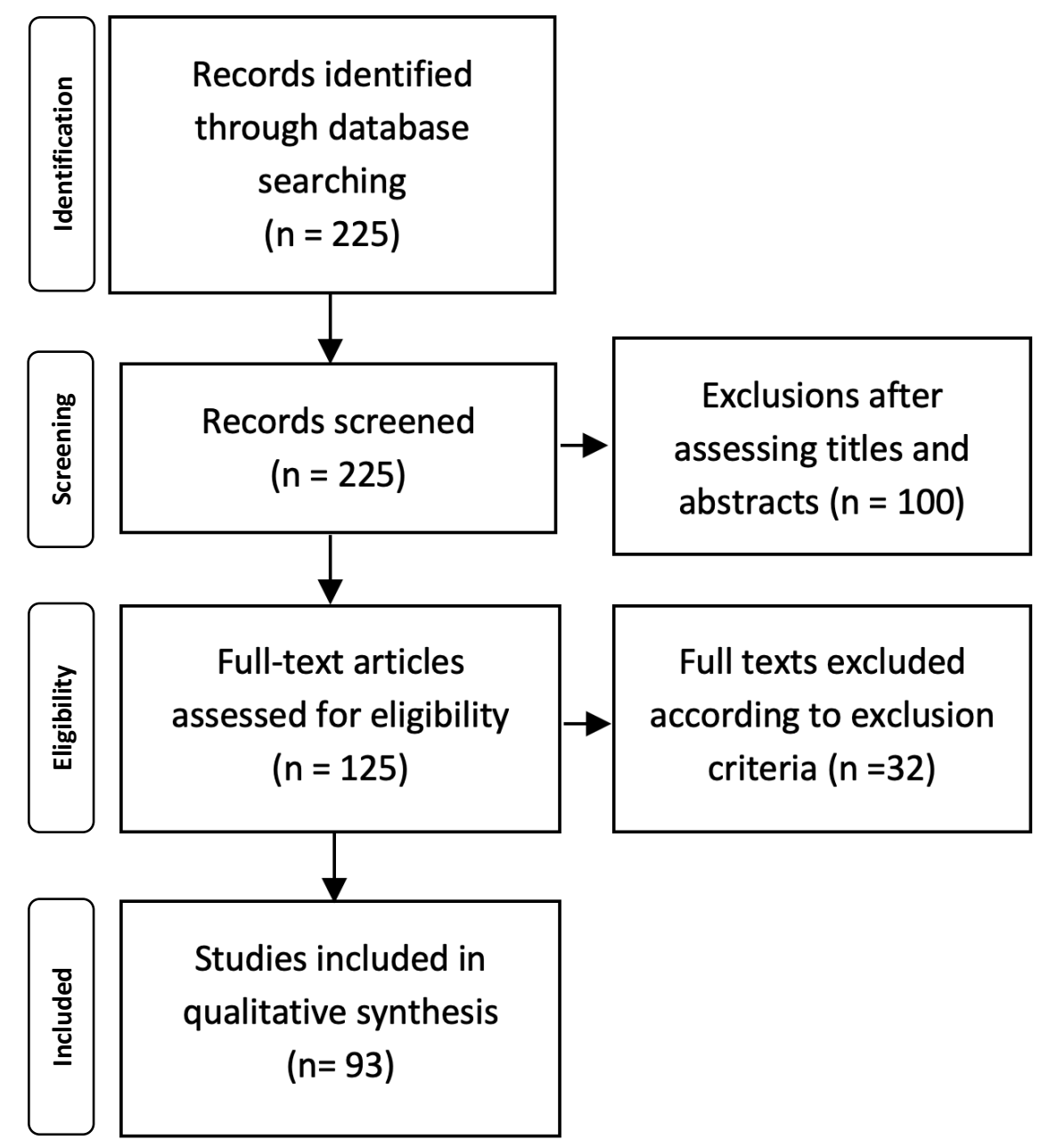

\section{Instruments, Diagnostic Criteria and identification methods for BE}

It was found a wide variety of instruments for the recognition of BED. These results are summarized in table 1 and table 2 . Below, it is briefly presented the main diagnostic methods that were used in the studies included in this review.

Table 1 - Instruments, Diagnostic criteria and identification methods used in the studies included in the review.

\begin{tabular}{lc}
\hline Method & Number of studies (\%) \\
\hline DSM IV or V + instrument & $61(65.60)$ \\
Only instrument & $26(27.95)$ \\
Only DSM IV or V & $06(6.45)$ \\
\hline
\end{tabular}

DSM - Diagnostic and Statistical Manual of Mental Disorders 
Table 2 - Instruments / scales used for binge eating identification

\begin{tabular}{|c|c|}
\hline Diagnostic criteria & $\begin{array}{c}\mathrm{N}^{\circ} \text { of } \\
\text { studies (\%) }\end{array}$ \\
\hline $\operatorname{DSM}^{9,14-15,17,19,23,26-85}$ & $67(72.04)$ \\
\hline $\begin{array}{l}\text { EDE - } Q^{14-15, ~ 19, ~ 27-29, ~ 33--35, ~ 37-~ 38, ~ 40, ~ 42-44, ~ 47-50, ~ 55-56, ~ 58-60, ~ 63-68, ~} \\
70-71,75-77,81-83,90-95\end{array}$ & $44(47.31)$ \\
\hline $\begin{array}{l}\operatorname{EDE} 14,17,27-28,30-33,39,45,47,50,52-53,55,57-58,62-64,68-71,73,78- \\
80,82-84,86-89\end{array}$ & 36 (38.70) \\
\hline BES 8-25 & 18 (19.35) \\
\hline YBOCS-BE $15,19,36,48,56,61,65$ & $07(7.52)$ \\
\hline TFEQ 15, 17, 19, 51, 65, 98-99 & $07(7.52)$ \\
\hline$E D I 31,53,66,78-80$ & $06(6.45)$ \\
\hline YFAS 20, 40, 93, 98 & $04(4.30)$ \\
\hline EDDS 72,96 & $02(2.15)$ \\
\hline LOCES $^{14,17}$ & $02(2.15)$ \\
\hline QEWP-R 97 & 01 (1.07) \\
\hline
\end{tabular}

BES - Binge Eating Scale; DSM - Diagnostic and Statistical Manual of Mental Disorders; EDDS - Eating Disorder Diagnostic Scale; EDE - Eating Disorder Examination; EDE -Q - Eating Disorder Examination Questionnaire; EDI - Eating Disorder Inventory; EDO-Q - Eating Disorder in Obesity Questionnaire, LOCES - Loss of Control Over Eating Scale; Q-EDD -

Questionnaire for Eating Disorder Diagnoses, QEWP-R -

Questionnaire on Eating and Weight Patterns - Revised; TFEQ -

Three-Factor Eating Questionnaire; YBOCS-BE - Yale-Brown

Obsessive Compulsive Scale Modified for Binge Eating; YFAS -

Yale Food Addiction Scale.

\section{Binge Eating Scale (BES) ${ }^{100}$}

The BES is a 16-item questionnaire used to assess the presence of binge eating behavior indicative of an eating disorder. It was originally developed to assess affective/cognitive aspects and behavioral manifestations of binge eating problems in obese individuals. This instrument has been widely used as a dimensional measure of the severity of binge eating, as a screening tool and as a useful instrument to assess treatment outcomes. The questions are based upon both behavioral characteristics (e.g., amount of food consumed) and the emotional, cognitive response, guilt or shame. Each question has 3-4 separate responses assigned a numerical value. The score range is from $0-46$, where:

Non-binging $<17$

Moderate binging $=18-26$

Severe binging $\geq 27$

\section{Diagnostic and Statistical Manual of Mental Disorders 4}

The Diagnostic and Statistical Manual of Mental Disorders, Fifth Edition (DSM-5) recognizes binge eating disorder (BED) as a distinct disorder, defined by binge episodes, during which an individual consumes an unusual large amount of food and 
experiences a sense of lack of control over his eating, but without the inappropriate compensatory behavior required by bulimia nervosa. Originally, BED was introduced in the 4 th edition of the DSM as a subcategory of Eating Disorder not Otherwise Specified (EDNOS) but is now a separated diagnostic entity. The DSM- 5 diagnostic criterion for BED included significant changes:

According to the DSM- 5 criteria, to be diagnosed as having Binge Eating Disorder a person must show:

A. Recurrent episodes of binge eating. An episode of binge eating is characterized by both of the following:

1. Eating, in a discrete period of time (e.g. within any 2-hour period), an amount of food that is definitely larger than most people would eat during a similar period of time and under similar circumstances.

2. A sense of lack of control over eating during the episode (e.g. a feeling that one cannot stop eating or control what or how much one is eating).

B. The binge eating episodes are associated with three or more of the following:

1. eating much more rapidly than normal

2. eating until feeling uncomfortably full

3. eating large amounts of food when not feeling physically hungry

4. eating alone because of feeling embarrassed by how much one is eating

5. feeling disgusted with oneself, depressed or very guilty afterward

C. Marked distress regarding binge eating is present

D. Binge eating occurs, on average, at least once a week for three months

E. Binge eating not associated with the recurrent use of inappropriate compensatory behaviors as in Bulimia Nervosa and does not occur exclusively during the course of Bulimia Nervosa, or Anorexia Nervosa methods to compensate for overeating, such as self-induced vomiting.

\section{Eating Disorder Examination (EDE) ${ }^{101}$}

The EDE is a semi-structured interview that assesses ED symptoms and psychopathology with a focus on the previous 28 days. The EDE assesses the frequency of different forms of overeating, including objective binge-eating episodes (Ex: large quantities of food with a subjective sense of loss of control) and subjective binge-eating episodes (Ex: episodes of loss of control while eating "subjectively" large quantities). The EDE also comprises four subscales (dietary restraint, eating concern, weight concern, and shape concern) the mean of which is 
a total global score reflecting ED psychopathology. Items are rated on 7-point forced-choice scales (range 0-6), with higher scores reflecting greater severity/frequency. The EDE is widely viewed as the "gold standard" measure of eating disorder psychopathology. It provides a measure of the range and severity of eating disorder features. It can also generate operational eating disorder diagnoses. It is used in most treatment studies and in many other investigations of eating disorder psychopathology. The current version of the EDE is edition 17.0D. The main difference from the earlier edition (16.0D) is that it is designed to generate DSM-5 eating disorder diagnoses.

\section{Eating Disorder Examination Questionnaire (EDE-Q) ${ }^{102}$}

The EDE-Q is a self-reported questionnaire based upon the EDE interview. Its use is indicated when it is impracticable or undesirable to employ the interview. The EDE$Q$ is very widely used and is also available in many languages. The current version is EDE-Q 6.0. The EDE-Q is a 33-item screener which measures disordered eating over a 28-day period and is scored across 4 sub-scales: Eating Concern, Shape Concern, Weight Concern and Dietary Restraint, as well as a global score, which is an average of the sub-scales.

\section{Eating Disorder Diagnostic Scale (EDDS) ${ }^{103}$}

The EDDS is a brief self-report scale, contains 22 items that diagnose eating disorders, such as anorexia nervosa, bulimia nervosa, and binge eating disorder. The EDDS was developed by adapting items from structured clinical interviews (EDE and SCID) and cross-referencing the diagnostic criteria from the current DSM at the time (DSM-IV).

\section{Eating Disorder Inventory (EDI) ${ }^{104}$}

The EDI is a self-reported questionnaire widely used both in research and in clinical settings to assess the symptoms and psychological features of eating disorders. The latest revision to the Eating disorder inventory; Eating disorder inventory-three (EDI-3) was released in 2004. It contains 91 items divided into twelve subscales rated on a $0-4$ point scoring system. Of this, three items are specific to eating disorders and nine are general psychological scales that, although not specific, are relevant to eating disorders. It yields six composites: Eating Disorder Risk, Ineffectiveness, Interpersonal Problems, Affective Problems, Overcontrol, General 
Mariana Escobar, Oellen Stuani Franzosi, Nathália Coelho, Silvia Chwartzmann Halpern, Juliana Nichterwitz Scherer, Felipe Ornell, Keila Maria Mendes Cereser, Neusa Sica da Rocha I Instruments for Binge Eating Assessment in Adults: a Systematic

Psychological Maladjustment. It is also a self-report questionnaire administered in twenty minutes.

\section{Loss of Control Over Eating Scale (LOCES) ${ }^{105}$}

The LOCES is a multidimensional scale designed to assess Loss of control eating in both clinical and nonclinical populations. Three factors of the LOCES emerged: (1) the behavioral aspects, (2) the cognitive/dissociative aspects, and (3) the positive/euphoric aspects. The two versions of LOCES are: with 24 items (original) and a short version with 7 items, as follows: $1=$ never to $5=$ very often, according to the description of the experience with eating in the last Eating Disorder Diagnosis 4 weeks.

\section{Three-Factor Eating Questionnaire (TFEQ) ${ }^{106}$}

The TFEQ is a self-assessment questionnaire designed to measure cognitive and behavioral components of eating in obese populations. It contains 51 items, aggregated into three scales: "Cognitive Restraint", "Disinhibition" and "Hunger". Each item scores either 0 or 1 point. The minimum score for factors I-II-III is therefore $0-0-0$, the possible maximum score $21-16-14$. There are reduced versions and also validated - TFEQ-18 and TFEQ-21.

Yale-Brown obsessive compulsive scale modified for binge eating (YBOCS-BE) ${ }^{19}$

The Yale-Brown Obsessive Compulsive Scale modified binge eating for measured obsessiveness of BE thoughts and compulsiveness of BE behaviors. Y-BOCS-BE total score ranges from 0 to 40, with higher scores indicating more severe symptoms.

\section{Yale Food Addiction Scale (YFAS) ${ }^{107}$}

The Yale Food Addiction Scale (YFAS) assesses addiction-like eating of palatable foods based on the seven diagnostic criteria for substance dependence in DSM-IV. The YFAS consists of 27 questions, 16 that assess the frequency of behaviors such as overeating and the experience of withdrawal symptoms, 8 yes/no questions that assess the impact of eating behaviors and success of trying to cut down on certain foods, and 3 questions that assess which foods the respondent finds problematic. The YFAS has been reported to have adequate internal reliability and convergent, discriminant, and incremental validity among undergraduates. 


\section{DISCUSSION}

This systematic review enabled us to describe the instruments and diagnostic criteria for Binge Eating Assessment for Adults used in CTs. The criteria or factors used to diagnose BE in the DSM are objective, and its severity and characterization are focused on the quantification of the binge eating episodes. Although in some items appear the feeling of "guilt" or "shame" the DSM does not assess specific issues about the intensity of these feelings, thoughts and sufferings. The scales (questionnaires) have several advantages in their use: many are easy, quick to administer, do not involve training, are efficient, economical, and capable of revealing behavior that, being considered shameful, could be omitted in an interview. They have disadvantages such as: not accurately evaluating some more complex concepts, which are better investigated by clinical interviews.

The Eating Disorder Examination (EDE) ${ }^{101}$, is a semi-structured clinical interview considered the gold standard in diagnosis of eating disorders, and also evaluates the severity of psychopathology with good levels of validity and reliability. However, EDE is a long questionnaire, taking an average of 60 minutes to complete. Thus, a faster version of EDE was adapted (15 minutes) and self-administered: the EDE- $Q$ ${ }^{102}$. This questionnaire has 36 items and provide a satisfactorily way to assess eating disorders also based on the four subscales. The Binge Eating (BES) ${ }^{100}$ is selfadministered questionnaire adequate to assess the interrelationships between binge eating, psychopathological symptoms and weight changes. BES is used to identify obese patients with binge eating and contributes to in planning of effective therapeutic strategies expanding knowledge of psychopathological symptoms.

This systematic review has some limitations. We restricted our search for studies published in English and we didn't perform a search in grey literature, thus the contribution of non-English reports and unpublished studies to our findings is unknown. Although we have not registered our protocol, the complete search strategy is available at Supplemental Content to enable the replication of the search.

The DSM-5 diagnostic criteria for BED it is considered an excellent diagnostic criteria, however, in our perception, if the objective is to identify emotional and qualitative issues, it could be included with the DMS- 5 a questionnaire or interview about subjective perceptions.

The questionnaires and interviews also assessed the feelings and behaviors involved in the individual's daily life, before, during and after episodes of binge eating, or 
even when the episode did not happen, but the thoughts were focused on this. When used in isolation questionnaires may even contain points of the DSM, however, for a full evaluation and diagnosis for to identify behavior and nutritional issues, the ideal would be to use a tool to assess the feelings and behavior as a whole, and also quantify the episodes. The most used instrument in the studies is the EDE interview and the EDE questionnaire; however, our perception is that, when used in association with DSM, any questionnaire presented in this review would be more complete as diagnostic method. We conclude that the best way to diagnose binge eating - qualitative and quantitative - is to use DSM with an instrument (any tool reported in this review).

\section{CONCLUSION}

The DSM- 5 diagnostic criterion for binge eating disorder is considered excellent and widely used, however, when the objective of the study is to identify emotional, nutritional and qualitative issues, a questionnaire or interview about subjective perceptions can be used in a complementary way.

\section{REFERÊNCIAS}

1. Treasure J, Claudino AM, Zucker N. Eating disorders. Lancet. 2010;375(9714):583-93.

2. Kontić O, Vasiljević N, Trisović M, Jorga J, Lakić A, Gasić MJ. Eating disorders. Srp Arh Celok Lek. 2012;140(9-10):673-8.

3. Hudson JI, Hiripi E, Pope HG, Kessler RC. The prevalence and correlates of eating disorders in the National Comorbidity Survey Replication. Biol Psychiatry. 2007;61(3):348-58.

4. Association AP. Diagnostic and statistical manual of mental disorders (DSM$\left.5^{\circledR}\right)$ : American Psychiatric Pub; 2013.

5. Goracci A, di Volo S, Casamassima F, Bolognesi S, Benbow J, Fagiolini A. Pharmacotherapy of binge-eating disorder: a review. J Addict Med. 2015;9(1):119.

6. Call C, Walsh BT, Attia E. From DSM-IV to DSM-5: changes to eating disorder diagnoses. Curr Opin Psychiatry. 2013;26(6):532-6.

7. Moher D, Liberati A, Tetzlaff J, Altman DG, Group P. Preferred reporting items for systematic reviews and meta-analyses: the PRISMA statement. Int J Surg. 2010;8(5):336-41.

8. Rieger E, Treasure J, Murray K, Caterson I. The use of support people to improve the weight-related and psychological outcomes of adults with obesity: A randomised controlled trial. Behav Res Ther. 2017; 94:48-59.

9. Silva Dos Santos PN, de Souza AL, Batista GA, Melhado-Kimura V, de Lima GA, Bahamondes L, et al. Binge eating and biochemical markers of appetite in new 
users of the contraceptive depot medroxyprogesterone acetate. Arch Gynecol Obstet. 2016;294(6):1331-6.

10. David LA, Sockalingam S, Wnuk S, Cassin SE. A pilot randomized controlled trial examining the feasibility, acceptability, and efficacy of Adapted Motivational Interviewing for post-operative bariatric surgery patients. Eat Behav. 2016; 22:87-92.

11. Zwickert K, Rieger E, Swinbourne J, Manns C, McAulay C, Gibson AA, et al. High or low intensity text-messaging combined with group treatment equally promote weight loss maintenance in obese adults. Obes Res Clin Pract. 2016;10(6):680-91.

12. Cassin SE, Sockalingam S, Du C, Wnuk S, Hawa R, Parikh SV. A pilot randomized controlled trial of telephone-based cognitive behavioural therapy for preoperative bariatric surgery patients. Behav Res Ther. 2016; 80:17-22.

13. Sockalingam S, Cassin SE, Wnuk S, Du C, Jackson T, Hawa R, et al. A Pilot Study on Telephone Cognitive Behavioral Therapy for Patients Six-Months PostBariatric Surgery. Obes Surg. 2017;27(3):670-5.

14. Palavras MA, Hay P, Touyz S, Sainsbury A, da Luz F, Swinbourne J, et al. Comparing cognitive behavioural therapy for eating disorders integrated with behavioural weight loss therapy to cognitive behavioural therapy-enhanced alone in overweight or obese people with bulimia nervosa or binge eating disorder: study protocol for a randomised controlled trial. Trials. 2015; 16:578.

15. McElroy SL, Mitchell JE, Wilfley D, Gasior M, Ferreira-Cornwell MC, McKay M, et al. Lisdexamfetamine Dimesylate Effects on Binge Eating Behaviour and Obsessive-Compulsive and Impulsive Features in Adults with Binge Eating Disorder. Eur Eat Disord Rev. 2016;24(3):223-31.

16. Goode RW, Ye L, Sereika SM, Zheng Y, Mattos M, Acharya SD, et al. Sociodemographic, anthropometric, and psychosocial predictors of attrition across behavioral weight-loss trials. Eat Behav. 2016; 20:27-33.

17. Maranhão MF, Estella NM, Cury ME, Amigo VL, Picasso CM, Berberian A, et al. The effects of repetitive transcranial magnetic stimulation in obese females with binge eating disorder: a protocol for a double-blinded, randomized, shamcontrolled trial. BMC Psychiatry. 2015; 15:194.

18. Robinson A, Safer DL, Austin JL, Etkin A. Does implicit emotion regulation in binge eating disorder matter? Eat Behav. 2015; 18:186-91.

19. Deal LS, Wirth RJ, Gasior M, Herman BK, McElroy SL. Validation of the yalebrown obsessive compulsive scale modified for binge eating. Int J Eat Disord. 2015;48(7):994-1004.

20. Mason AE, Lustig RH, Brown RR, Acree M, Bacchetti P, Moran PJ, et al. Acute responses to opioidergic blockade as a biomarker of hedonic eating among obese women enrolled in a mindfulness-based weight loss intervention trial. Appetite. 2015;91:311-20.

21. Robert SA, Rohana AG, Shah SA, Chinna K, Wan Mohamud WN, Kamaruddin NA. Improvement in binge eating in non-diabetic obese individuals after 3 months of treatment with liraglutide - A pilot study. Obes Res Clin Pract. 2015;9(3):3014. 
22. Braden AL, Madowitz J, Matheson BE, Bergmann K, Crow SJ, Boutelle KN. Parent binge eating and depressive symptoms as predictors of attrition in a familybased treatment for pediatric obesity. Child Obes. 2015;11(2):165-9.

23. Farci AM, Piras S, Murgia M, Chessa A, Restivo A, Gessa GL, et al. Disulfiram for binge eating disorder: an open trail. Eat Behav. 2015;16:84-7.

24. Danielsen KK, Sundgot-Borgen J, Mæhlum S, Svendsen M. Beyond weight reduction: improvements in quality of life after an intensive lifestyle intervention in subjects with severe obesity. Ann Med. 2014;46(5):273-82.

25. Ziauddeen H, Chamberlain SR, Nathan PJ, Koch A, Maltby K, Bush M, et al. Effects of the mu-opioid receptor antagonist GSK1521498 on hedonic and consummatory eating behaviour: a proof of mechanism study in binge-eating obese subjects. Mol Psychiatry. 2013;18(12):1287-93.

26. Turton R, Nazar BP, Burgess EE, Lawrence NS, Cardi V, Treasure J, et al. To Go or Not to Go: A Proof of Concept Study Testing Food-Specific Inhibition Training for Women with Eating and Weight Disorders. Eur Eat Disord Rev. 2018;26(1):1121.

27. Kenny TE, Singleton C, Carter JC. Testing predictions of the emotion regulation model of binge-eating disorder. Int J Eat Disord. 2017;50(11):1297-305.

28. Hildebrandt T, Michaelides A, Mackinnon D, Greif R, DeBar L, Sysko R. Randomized controlled trial comparing smartphone assisted versus traditional guided self-help for adults with binge eating. Int J Eat Disord. 2017;50(11):131322.

29. Preuss H, Pinnow M, Schnicker K, Legenbauer T. Improving Inhibitory Control Abilities (ImpulsE)-A Promising Approach to Treat Impulsive Eating? Eur Eat Disord Rev. 2017;25(6):533-43.

30. Mason TB, Crosby RD, Kolotkin RL, Grilo CM, Mitchell JE, Wonderlich SA, et al. Correlates of weight-related quality of life among individuals with binge eating disorder before and after cognitive behavioral therapy. Eat Behav. 2017;27:1-6.

31. Ferrer-García M, Gutiérrez-Maldonado J, Pla-Sanjuanelo J, Vilalta-Abella F, Riva G, Clerici M, et al. A Randomised Controlled Comparison of Second-Level Treatment Approaches for Treatment-Resistant Adults with Bulimia Nervosa and Binge Eating Disorder: Assessing the Benefits of Virtual Reality Cue Exposure Therapy. Eur Eat Disord Rev. 2017;25(6):479-90.

32. de Zwaan M, Herpertz S, Zipfel S, Svaldi J, Friederich HC, Schmidt F, et al. Effect of Internet-Based Guided Self-help vs Individual Face-to-Face Treatment on Full or Subsyndromal Binge Eating Disorder in Overweight or Obese Patients: The INTERBED Randomized Clinical Trial. JAMA Psychiatry. 2017;74(10):98795.

33. Schmitz F, Svaldi J. Effects of Bias Modification Training in Binge Eating Disorder. Behav Ther. 2017;48(5):707-17.

34. Hudson JI, McElroy SL, Ferreira-Cornwell MC, Radewonuk J, Gasior M. Efficacy of Lisdexamfetamine in Adults With Moderate to Severe Binge-Eating Disorder: A Randomized Clinical Trial. JAMA Psychiatry. 2017;74(9):903-10.

35. Mathisen TF, Rosenvinge JH, Pettersen G, Friborg O, Vrabel K, Bratland-Sanda $S$, et al. The PED-t trial protocol: The effect of physical exercise - and dietary 
therapy compared with cognitive behavior therapy in treatment of bulimia nervosa and binge eating disorder. BMC Psychiatry. 2017;17(1):180.

36. McElroy SL, Hudson JI, Gasior M, Herman BK, Radewonuk J, Wilfley D, et al. Time course of the effects of lisdexamfetamine dimesylate in two phase 3, randomized, double-blind, placebo-controlled trials in adults with bingeeating disorder. Int J Eat Disord. 2017;50(8):884-92.

37. Gasior M, Hudson J, Quintero J, Ferreira-Cornwell MC, Radewonuk J, McElroy SL. A Phase 3, Multicenter, Open-Label, 12-Month Extension Safety and Tolerability Trial of Lisdexamfetamine Dimesylate in Adults With Binge Eating Disorder. J Clin Psychopharmacol. 2017;37(3):315-22.

38. Simpson CC, Mazzeo SE. Attitudes toward orthorexia nervosa relative to DSM- 5 eating disorders. Int J Eat Disord. 2017;50(7):781-92.

39. Davidsen AH, Poulsen S, Lindschou J, Winkel P, Tróndarson MF, Waaddegaard $M$, et al. Feedback in group psychotherapy for eating disorders: A randomized clinical trial. J Consult Clin Psychol. 2017;85(5):484-94.

40. Giel KE, Speer E, Schag K, Leehr EJ, Zipfel S. Effects of a food-specific inhibition training in individuals with binge eating disorder-findings from a randomized controlled proof-of-concept study. Eat Weight Disord. 2017;22(2):345-51.

41. Barnes RD, Barber JA. Preliminary examination of metabolic syndrome response to motivational interviewing for weight loss as compared to an attentional control and usual care in primary care for individuals with and without bingeeating disorder. Eat Behav. 2017; 26:108-13.

42. Haynos AF, Roberto CA. The effects of restaurant menu calorie labeling on hypothetical meal choices of females with disordered eating. Int J Eat Disord. 2017;50(3):275-83.

43. Russell SL, Haynos AF, Crow SJ, Fruzzetti AE. An experimental analysis of the affect regulation model of binge eating. Appetite. 2017; 110:44-50.

44. de Jong M, Korrelboom K, van der Meer I, Deen M, Hoek HW, Spinhoven P. Effectiveness of enhanced cognitive behavioral therapy (CBT-E) for eating disorders: study protocol for a randomized controlled trial. Trials. 2016;17(1):573.

45. Chen EY, Cacioppo J, Fettich K, Gallop R, McCloskey MS, Olino T, et al. An adaptive randomized trial of dialectical behavior therapy and cognitive behavior therapy for binge-eating. Psychol Med. 2017;47(4):703-17.

46. Sala M, Breithaupt L, Bulik CM, Hamer RM, La Via MC, Brownley KA. A DoubleBlind, Randomized Pilot Trial of Chromium Picolinate for Overweight Individuals with Binge-Eating Disorder: Effects on Glucose Regulation. J Diet Suppl. 2017;14(2):191-9.

47. Schag K, Leehr EJ, Skoda EM, Becker S, Zipfel S, Giel KE. [Impulsivity-focused Group Intervention to reduce Binge Eating Episodes in Patients with Binge Eating Disorder - A Group Training Program]. Psychother Psychosom Med Psychol. 2016;66(11):449-54.

48. Guerdjikova AI, Mori N, Blom TJ, Keck PE, Williams SL, Welge JA, et al. Lisdexamfetamine dimesylate in binge eating disorder: a placebo controlled trial. Hum Psychopharmacol. 2016;31(5):382-91. 
49. Haynos AF, Hill B, Fruzzetti AE. Emotion regulation training to reduce problematic dietary restriction: An experimental analysis. Appetite. 2016; 103:265-74.

50. Wagner B, Nagl M, Dölemeyer R, Klinitzke G, Steinig J, Hilbert A, et al. Randomized Controlled Trial of an Internet-Based Cognitive-Behavioral Treatment Program for Binge-Eating Disorder. Behav Ther. 2016;47(4):500-14.

51. Ruffault A, Carette C, Lurbe I Puerto K, Juge N, Beauchet A, Benoliel JJ, et al. Randomized controlled trial of a 12-month computerized mindfulness-based intervention for obese patients with binge eating disorder: The MindOb study protocol. Contemp Clin Trials. 2016; 49:126-33.

52. Manasse SM, Espel HM, Schumacher LM, Kerrigan SG, Zhang F, Forman EM, et al. Does impulsivity predict outcome in treatment for binge eating disorder? A multimodal investigation. Appetite. 2016; 105:172-9.

53. McIntosh VVW, Jordan J, Carter JD, Frampton CMA, McKenzie JM, Latner JD, et al. Psychotherapy for transdiagnostic binge eating: A randomized controlled trial of cognitive-behavioural therapy, appetite-focused cognitive-behavioural therapy, and schema therapy. Psychiatry Res. 2016; 240:412-20.

54. Davis C, Levitan RD, Kaplan AS, Carter-Major JC, Kennedy JL. Sex differences in subjective and objective responses to a stimulant medication

(methylphenidate): Comparisons between overweight/obese adults with and without binge-eating disorder. Int J Eat Disord. 2016;49(5):473-81.

55. Schag K, Leehr EJ, Martus P, Bethge W, Becker S, Zipfel S, et al. Impulsivityfocused group intervention to reduce binge eating episodes in patients with binge eating disorder: study protocol of the randomised controlled IMPULS trial. BMJ Open. 2015;5(12):e009445.

56. McElroy SL, Hudson J, Ferreira-Cornwell MC, Radewonuk J, Whitaker T, Gasior M. Lisdexamfetamine Dimesylate for Adults with Moderate to Severe Binge Eating Disorder: Results of Two Pivotal Phase 3 Randomized Controlled Trials. Neuropsychopharmacology. 2016;41(5):1251-60.

57. Pisetsky EM, Durkin NE, Crosby RD, Berg KC, Mitchell JE, Crow SJ, et al. Examination of early group dynamics and treatment outcome in a randomized controlled trial of group cognitive behavior therapy for binge eating disorder. Behav Res Ther. 2015; 73:74-8.

58. Schmitz F, Naumann E, Biehl S, Svaldi J. Gating of attention towards food stimuli in binge eating disorder. Appetite. 2015; 95:368-74.

59. Svaldi J, Naumann E, Biehl S, Schmitz F. Impaired Early-Response Inhibition in Overweight Females with and without Binge Eating Disorder. PLoS One. 2015;10(7):e0133534.

60. ter Huurne ED, de Haan HA, Postel MG, van der Palen J, VanDerNagel JE, DeJong CA. Web-Based Cognitive Behavioral Therapy for Female Patients With Eating Disorders: Randomized Controlled Trial. J Med Internet Res. 2015;17(6): e152.

61. McElroy SL, Guerdjikova AI, Mori N, Blom TJ, Williams S, Casuto LS, et al. Armodafinil in binge eating disorder: a randomized, placebo-controlled trial. Int Clin Psychopharmacol. 2015;30(4):209-15. 
62. Hilbert A, Hildebrandt T, Agras WS, Wilfley DE, Wilson GT. Rapid response in psychological treatments for binge eating disorder. J Consult Clin Psychol. 2015;83(3):649-54.

63. Grilo CM, White MA, Masheb RM, Gueorguieva R. Predicting meaningful outcomes to medication and self-help treatments for binge-eating disorder in primary care: The significance of early rapid response. J Consult Clin Psychol. 2015;83(2):387-94.

64. Kass AE, Wang AZ, Kolko RP, Holland JC, Altman M, Trockel M, et al. Identification as overweight by medical professionals: relation to eating disorder diagnosis and risk. Eat Behav. 2015; 17:62-8.

65. McElroy SL, Hudson JI, Mitchell JE, Wilfley D, Ferreira-Cornwell MC, Gao J, et al. Efficacy and safety of lisdexamfetamine for treatment of adults with moderate to severe binge-eating disorder: a randomized clinical trial. JAMA Psychiatry. 2015;72(3):235-46.

66. Völker U, Jacobi C, Trockel MT, Taylor CB. Moderators and mediators of outcome in Internet-based indicated prevention for eating disorders. Behav Res Ther. $2014 ; 63: 114-21$.

67. Kelly AC, Carter JC. Self-compassion training for binge eating disorder: a pilot randomized controlled trial. Psychol Psychother. 2015;88(3):285-303.

68. Alfonsson S, Parling T, Ghaderi A. Group behavioral activation for patients with severe obesity and binge eating disorder: a randomized controlled trial. Behav Modif. 2015;39(2):270-94.

69. Brauhardt A, de Zwaan M, Herpertz S, Zipfel S, Svaldi J, Friederich HC, et al. Therapist adherence in individual cognitive-behavioral therapy for bingeeating disorder: assessment, course, and predictors. Behav Res Ther. 2014; 61:55-60.

70. Svaldi J, Naumann E. Effects of rumination and acceptance on body dissatisfaction in binge eating disorder. Eur Eat Disord Rev. 2014;22(5):338-45.

71. Fischer S, Meyer AH, Dremmel D, Schlup B, Munsch S. Short-term cognitivebehavioral therapy for binge eating disorder: long-term efficacy and predictors of long-term treatment success. Behav Res Ther. 2014; 58:36-42.

72. Pacanowski CR, Senso MM, Oriogun K, Crain AL, Sherwood NE. Binge eating behavior and weight loss maintenance over a 2-year period. J Obes. 2014; 2014:249315.

73. Grilo CM, Masheb RM, White MA, Gueorguieva R, Barnes RD, Walsh BT, et al. Treatment of binge eating disorder in racially and ethnically diverse obese patients in primary care: randomized placebo-controlled clinical trial of selfhelp and medication. Behav Res Ther. 2014; 58:1-9.

74. Zendegui EA, West JA, Zandberg LJ. Binge eating frequency and regular eating adherence: the role of eating pattern in cognitive behavioral guided self-help. Eat Behav. 2014;15(2):241-3.

75. Vella-Zarb RA, Mills JS, Westra HA, Carter JC, Keating L. A Randomized controlled trial of motivational interviewing + self-help versus psychoeducation + self-help for binge eating. Int J Eat Disord. 2015;48(3):32832. 
76. Kekic M, McClelland J, Campbell I, Nestler S, Rubia K, David AS, et al. The effects of prefrontal cortex transcranial direct current stimulation (tDCS) on food craving and temporal discounting in women with frequent food cravings. Appetite. 2014; 78:55-62.

77. Svaldi J, Tuschen-Caffier B, Trentowska M, Caffier D, Naumann E. Differential caloric intake in overweight females with and without binge eating: effects of a laboratory-based emotion-regulation training. Behav Res Ther. 2014; 56:39-46.

78. Martinsen M, Bahr R, Børresen R, Holme I, Pensgaard AM, Sundgot-Borgen J. Preventing eating disorders among young elite athletes: a randomized controlled trial. Med Sci Sports Exerc. 2014;46(3):435-47.

79. Klein AS, Skinner JB, Hawley KM. Targeting binge eating through components of dialectical behavior therapy: preliminary outcomes for individually supported diary card self-monitoring versus group-based DBT. Psychotherapy (Chic). 2013;50(4):543-52.

80. Jordan J, McIntosh VV, Carter JD, Rowe S, Taylor K, Frampton CM, et al. Bulimia nervosa-nonpurging subtype: closer to the bulimia nervosa-purging subtype or to binge eating disorder? Int J Eat Disord. 2014;47(3):231-8.

81. ter Huurne ED, Postel MG, de Haan HA, DeJong CA. Effectiveness of a web-based treatment program using intensive therapeutic support for female patients with bulimia nervosa, binge eating disorder and eating disorders not otherwise specified: study protocol of a randomized controlled trial. BMC Psychiatry. 2013; 13:310.

82. Grilo CM, White MA, Gueorguieva R, Barnes RD, Masheb RM. Self-help for binge eating disorder in primary care: a randomized controlled trial with ethnically and racially diverse obese patients. Behav Res Ther. 2013;51(12):855-61.

83. Masson PC, von Ranson KM, Wallace LM, Safer DL. A randomized wait-list controlled pilot study of dialectical behaviour therapy guided self-help for binge eating disorder. Behav Res Ther. 2013;51(11):723-8.

84. Peterson CB, Crosby RD, Wonderlich SA, Mitchell JE, Crow SJ, Engel S. Predicting group cognitive-behavioral therapy outcome of binge eating disorder using empirical classification. Behav Res Ther. 2013;51(9):526-32.

85. Reyes-Rodríguez ML, Gulisano M, Silva Y, Pivarunas B, Luna-Reyes KL, Bulik CM. "Las penas con pan duelen menos": The role of food and culture in Latinas with disordered eating behaviors. Appetite. 2016; 100:102-9.

86. Lowe MR, Arigo D, Butryn ML, Gilbert JR, Sarwer D, Stice E. Hedonic hunger prospectively predicts onset and maintenance of loss of control eating among college women. Health Psychol. 2016;35(3):238-44.

87. Barnes RD, White MA, Martino S, Grilo CM. A randomized controlled trial comparing scalable weight loss treatments in primary care. Obesity (Silver Spring). 2014;22(12):2508-16.

88. Manasse SM, Juarascio AS, Forman EM, Berner LA, Butryn ML, Ruocco AC. Executive functioning in overweight individuals with and without loss-ofcontrol eating. Eur Eat Disord Rev. 2014;22(5):373-7.

89. Conceição EM, Crosby R, Mitchell JE, Engel SG, Wonderlich SA, Simonich HK, et al. Picking or nibbling: frequency and associated clinical features in bulimia 
nervosa, anorexia nervosa, and binge eating disorder. Int J Eat Disord. 2013;46(8):815-8.

90. Racine SE, Hebert KR, Benning SD. Emotional Reactivity and Appraisal of Food in Relation to Eating Disorder Cognitions and Behaviours: Evidence to Support the Motivational Conflict Hypothesis. Eur Eat Disord Rev. 2018;26(1):3-10.

91. Smith E, Whittingham C. Cognitive remediation therapy plus behavioural weight loss compared to behavioural weight loss alone for obesity: study protocol for a randomised controlled trial. Trials. 2017;18(1):42.

92. Aardoom JJ, Dingemans AE, Fokkema M, Spinhoven P, Van Furth EF. Moderators of change in an Internet-based intervention for eating disorders with different levels of therapist support: What works for whom? Behav Res Ther. 2017; 89:6674 .

93. Frayn M, Sears CR, von Ranson KM. A sad mood increases attention to unhealthy food images in women with food addiction. Appetite. 2016; 100:55-63.

94. Schmidt J, Martin A. Neurofeedback Against Binge Eating: A Randomized Controlled Trial in a Female Subclinical Threshold Sample. Eur Eat Disord Rev. 2016;24(5):406-16.

95. Jenkins PE, Luck A, Burrows A, Boughton N. Comparison of face-to-face versus email guided self-help for binge eating: study protocol for a randomised controlled trial. Trials. 2014; 15:181.

96. Hopkins LB, Medina JL, Baird SO, Rosenfield D, Powers MB, Smits JA. Heated hatha yoga to target cortisol reactivity to stress and affective eating in women at risk for obesity-related illnesses: A randomized controlled trial. J Consult Clin Psychol. 2016;84(6):558-64.

97. Chao AM, Wadden TA, Gorin AA, Shaw Tronieri J, Pearl RL, Bakizada ZM, et al. Binge Eating and Weight Loss Outcomes in Individuals with Type 2 Diabetes: 4Year Results from the Look AHEAD Study. Obesity (Silver Spring). 2017;25(11):1830-7.

98. Hardman CA, Rogers PJ, Dallas R, Scott J, Ruddock HK, Robinson E. "Food addiction is real". The effects of exposure to this message on self-diagnosed food addiction and eating behaviour. Appetite. 2015; 91:179-84.

99. Bravo GL, Poje AB, Perissinotti I, Marcondes BF, Villamar MF, Manzardo AM, et al. Transcranial direct current stimulation reduces food-craving and measures of hyperphagia behavior in participants with Prader-Willi syndrome. Am J Med Genet B Neuropsychiatr Genet. 2016;171B(2):266-75.

100. Gormally J, Black S, Daston S, Rardin D. The assessment of binge eating severity among obese persons. Addict Behav. 1982;7(1):47-55.

101. Cooper Z, Cooper PJ, Fairburn CG. The validity of the eating disorder examination and its subscales. Br J Psychiatry. 1989; 154:807-12.

102. Fairburn CG, Beglin SJ. Assessment of eating disorders: interview or self-report questionnaire? Int J Eat Disord. 1994;16(4):363-70.

103. Stice E, Fisher M, Martinez E. Eating disorder diagnostic scale: additional evidence of reliability and validity. Psychol Assess. 2004;16(1):60-71.

104. Garner DM. EDI-3, Eating Disorder Inventory-3: Professional Manual. Psychological Assessment Resources, Incorporated.; 2004. 
Mariana Escobar, Oellen Stuani Franzosi, Nathália Coelho, Silvia Chwartzmann Halpern, Juliana Nichterwitz Scherer, Felipe Ornell, Keila Maria Mendes Cereser, Neusa Sica da Rocha I Instruments for Binge Eating Assessment in Adults: a Systematic Review

105. Latner JD, Mond JM, Kelly MC, Haynes SN, Hay PJ. The Loss of Control Over Eating Scale: development and psychometric evaluation. Int J Eat Disord. 2014;47(6):647-59.

106. Stunkard AJ, Messick S. The three-factor eating questionnaire to measure dietary restraint, disinhibition and hunger. J Psychosom Res. 1985;29(1):71-83.

107. Gearhardt AN, Corbin WR, Brownell KD. Preliminary validation of the Yale Food Addiction Scale. Appetite. 2009;52(2):430-6.

Submissão: 19/03/2019

Aprovação: 20/12/2020 